\title{
Formação de Estratégias Socioambientais Corporativas: os Jogos Aracruz Celulose-Partes Interessadas
}

\author{
José Célio Silveira Andrade
}

\begin{abstract}
Resumo
Este artigo tem por objetivo analisar as interações de Aracruz Celulose com as partes interessadas (stakeholders) durante o processo de formação de estratégias socioambientais corporativas no que tange, particularmente, às demandas de mercado, de regulação e de comunicação. Para alcançar este objetivo, o trabalho utiliza-se da estratégia metodológica de estudo de caso, complementada por técnicas de análise documental, entrevistas semi-estruturadas e observação não-participante. Por meio de uma grade analítica, construída a partir de premissas das abordagens teóricas dos jogos coopetitivos e stakeholders, neste estudo de caso argumenta-se que para administrar a tensão inerente aos seus interesses corporativos e àqueles dos stakeholders, a Aracruz identifica os elementos mais importantes desses jogos socioambientais e formula estratégias para influenciá-los mediante o planejamento de um sistema de representação e defesa dos seus interesses. Salienta-se que a grade analítica utilizada privilegiou a compreensão da face racional-voluntarista do processo de formação de estratégias socioambientais da Aracruz, e recomenda-se uma análise deste processo não somente por meio do intercâmbio racional como locus de formação de estratégias corporativas, mas também como processo sociopolítico moldado por regras, normas e convenções institucionalizadas.
\end{abstract}

Palavras-chaves: Aracruz Celulose; partes interessadas; estratégias socioambientais corporativas; jogos coopetitivos.

\begin{abstract}
This paper examines the interactions between the pulp and paper company Aracruz Celulose and its stakeholders, as part of the process of definition of this corporate social and environmental strategies that represents a response to market demands, regulation and the need for communication with stakeholders. For the analysis, a case study methodological approach is adopted, using three research methods: documentary analysis, semi-structured interviews and non-participant observation. An analytical framework based on both the theory of co-opetitive games and the stakeholder theory is used. The paper argues that in order to manage conflicts between its corporate interests and the stakeholders' demands, Aracruz identifies the most important elements of the social and environmental games and formulates strategies to influence those elements through a network of representation that, ultimately, meets its own interests. It is stressed that the chosen analytical framework theory is based on the understanding of the voluntary and rational side of social and environmental strategies adopted by Aracruz. However, besides the rational side, this paper recommends that the analysis of this process would also contemplate the social and political contexts, which are determined by rules, norms and institutionalized conventions.
\end{abstract}

Key words: Aracruz Celulose; stakeholders; corporate social and environmental strategies; coopetitive games. 


\section{INTRODUÇÃO}

A partir da década de 90, com o esgotamento do antigo jogo socioambiental entre empresa-agência governamental de controle ambiental, pautado no planejamento técnico-econômico, o ambientalismo corporativo tem enfrentado como um dos principais desafios a emergência de novos atores socioambientais no processo de formação de estratégias empresariais. Uma grande diversidade de grupos de interesse - consumidores, competidores, organizações sociais e ambientais, populações tradicionais etc. - denominados stakeholders, vem exercendo pressão sobre os rumos estratégicos das organizações e estabelecendo novo padrão para os jogos socioambientais.

Neste contexto, a legitimidade da empresa passa a ser vista como a sua capacidade de construir estratégias socioambientais, que integrem, de maneira sinérgica, aspectos econômicos, ambientais e sociais e contemplem satisfatoriamente as demandas desses múltiplos atores, localizados num ambiente institucional cada vez mais controvertido. Estas demandas socioambientais, refletidas em estudos, normas, regulações, leis, inovações tecnológicas, estratégias de marketing e comunicação corporativas, balanços socioambientais, vêm afetando o sistema produtivo mundial e, particularmente, as empresas do complexo agroindustrial de celulose de mercado.

Assim, dado que as relações empresa-stakeholders apresentam objetivos distintos e acomodam numerosos conflitos de interesses, torna-se necessário compreender como as empresas formulam processos visando à integração de stakeholders heterogêneos durante a formação das suas estratégias socioambientais corporativas. Constatada a pouca exploração, por parte dos pesquisadores de estratégia empresarial, das relações das empresas com o seu ambiente institucional e analisadas as insuficiências das abordagens teóricas que tratam da construção das estratégias socioambientais, partiu-se para a construção de uma grade de análise, fruto da conversação entre premissas das abordagens teóricas dos jogos coopetitivos e stakeholders. A grade de leitura construída lança luz sobre a formação das estratégias socioambientais em organizações empresariais, que experimentam a influência crescente, no seu ambiente institucional, de stakeholders que contestam, permanentemente, a sua legitimidade.

Assim, este artigo tem por objetivo central analisar, a partir da ótica proporcionada pela grade analítica utilizada, as interações da Aracruz Celulose com as 
partes interessadas (stakeholders) durante o processo de formação de estratégias socioambientais corporativas no que tange, particularmente, às demandas de mercado, de regulação e de comunicação. Para alcançar esse objetivo, o trabalho utiliza-se da estratégia metodológica intitulada estudo de caso, fundamentado em informações e dados secundários, extraídos de documentos internos, relatórios e publicações técnico-científicas. Por meio da utilização da técnica de triangulação de instrumentos de coleta, os dados secundários foram complementados com dados primários, obtidos pela pesquisa de campo em observações não-participantes e entrevistas semi-estruturadas com informanteschaves.

\section{Abordagens Teóricas dos Jogos Coopetitivos e Stakeholders: o Intercâmbio Racional como locus de Formação de EstratÉGIAS}

A abordagem da teoria dos jogos, envolvendo jogos mais amplos, que combinam conflito e cooperação, constitui-se no ponto de partida, complementado, posteriormente, com a abordagem teórica dos stakeholders, para a construção de uma grade analítica que possibilite a compreensão das interações estratégicas da empresa com os stakeholders durante o processo de formação de estratégias socioambientais corporativas. Para tal, a ênfase, aqui, não será dada nem aos jogos de conflito puro (jogos de soma zero) nem aos jogos de cooperação pura (nos quais os atores envolvidos formam estratégias conjuntamente e determinam equilíbrios). Estas abordagens clássicas da teoria dos jogos mostraram-se muito limitadas para espelhar as interações da vida real.

Esta decisão foi tomada a partir da premissa, corroborada por Dixit e Nalebuff (1994) e Brandenburger e Nalebuff (1995), de que os atores sociais estratégicos entram em conflito para buscar a cooperação, por meio de jogos que mesclam momentos de conflito e cooperação, aqui denominados jogos coopetitivos. Isto é, tanto a empresa quanto os stakeholders são prisioneiros de um mesmo dilema: Como alcançar a cooperação que pode emergir de jogos não-cooperativos nos quais as estratégias são construídas individualmente por cada ator?

Tentar encontrar respostas para esta pergunta, que solucionem este dilema, sempre foi uma das preocupações da teoria dos jogos, área de pesquisa fundada no final da década de 40. Desde então, jogo passou a ser uma espécie de metáfora científica para situações de interação de indivíduos, na qual o resultado de suas decisões depende fundamentalmente das decisões de outros indivíduos en- 
volvidos na mesma situação (Simonsen, 1997). Na economia, a teoria dos jogos tem sido usada para examinar a concorrência e a cooperação no ambiente dos negócios corporativos. A partir daí, difundiu-se para diversos campos do conhecimento, como, por exemplo, a administração. Pode-se dizer que a teoria dos jogos é uma abordagem teórica interdisciplinar para o estudo racional do comportamento humano em situações de interdependência estratégica.

Assim, para a teoria dos jogos, as interações dos atores podem ser descritas e analisadas como jogos de interdependência estratégica, nos quais o interesse de cada participante é maximizar o seu ganho individual. Esse ganho, por sua vez, depende das ações escolhidas não apenas por um jogador, mas também pelos demais participantes. Esta é, por exemplo, a perspectiva adotada pela teoria dos jogos em sua versão tradicional (Von Neumann e Morgenstern apud Lecomte, 1998), ao prescrever fórmulas de modelização matemática para a antecipação de soluções em situações marcadas pelo conflito do tipo ganha-perde, onde não é prevista a possibilidade de ganhos mútuos (soma não-nula) entre as partes.

Considerando a dependência entre ganho individual e ações escolhidas, a teoria dos jogos tradicional parte da premissa de que o jogo é o locus de formação de estratégias numa situação de incerteza, caracterizada pela interação racional, em que os atores tentam antecipar as ações dos outros com os quais interagem, por considerar que o alcance de seus objetivos depende, também, daquelas ações. A estratégia, portanto, é definida como opção, ou conjunto de opções, que especifica as escolhas que possuem os jogadores em cada situação, levando-se em consideração o posicionamento dos demais participantes. Logo, as estratégias são formadas pela interação dos atores, fazendo com que o seu processo de formação seja analisado por meio do estudo e interpretação dos jogos entre atores. Ao analisar as interações racionais, a teoria dos jogos tradicional assume a individualidade dos atores em contexto de incerteza estratégica.

Ao admitir a formação das decisões estratégicas como processo analítico, a partir do estudo racional compreensivo da relação entre as posições dos jogadores no cenário competitivo e nos jogos das forças de mercado, o processo de formação de estratégia, defendido pela teoria dos jogos, foi classificado por Mintzberg, Ahlstrand e Hampel (2000) na Escola de Posicionamento, inspirada nas abordagens teóricas econômicas e, em particular, na área de organização industrial, que tem como premissa básica a formação da estratégia como processo analítico dedutivo.

O exemplo mais conhecido da teoria dos jogos é o assim chamado Dilema dos Prisioneiros, popularizado pelo matemático A. W. Tucker e utilizado por Dawes (apud Milani, 1998) para formalização do modelo intitulado Tragédia dos Co- 
muns, que tenta explicar como a regulação social pode estabelecer-se, levandose em consideração a problemática dos bens comuns, em geral, e da questão socioambiental, em particular.

O interessante desse modelo é que ele estabelece um protótipo: o do jogo em que a racionalidade individual pode ser coletivamente irracional, ilustrando como a maximização dos resultados individuais pode ser prejudicial à coletividade. É esse contraste perverso entre boas intenções e maus resultados que torna o Dilema dos Prisioneiros relevante para uma ampla gama de situações estratégicas, em que a concorrência sem limites produziria resultados prejudiciais para todos. Nesses casos, a cooperação é preferível a uma concorrência implacável. Contudo, a transformação do jogo não-cooperativo (jogo de soma zero) de concorrência em um jogo de soma positiva de cooperação não ocorre, a menos que outras estratégias possam ser encontradas.

A identificação da lógica perversa da não-cooperação incondicional do free rider - estrutura de escolhas racionais representada pelo Dilema dos Prisioneiros, deu forma definitiva ao problema de como conciliar a premissa de racionalidade ilimitada com a possibilidade de cooperação. Visando encontrar estratégias que conseguissem romper com a questão da impossibilidade da ação coletiva, de tal modo que o grau de cooperação entre agentes pudesse mostrar-se superior à estrita aplicação do princípio da racionalidade, inúmeras soluções teóricas parecem ter sido encontradas para o problema de articulação entre racionalidade e ação coletiva.

A abordagem teórica dos jogos coopetitivos, trabalhada por Dixit e Nalebuff (1994), Brandenburger e Nelebuff (1995) e Rothschild (1995), alguns dos responsáveis pela popularização do uso da teoria dos jogos nas pesquisas sobre estratégia empresarial corporativa, aparece como uma das tentativas de encontrar estruturas alternativas ao Dilema dos Prisioneiros. Preocupada em como fazer para que esse dilema não permaneça como uma representação válida e evolua para estruturas mais favoráveis ao comportamento cooperativo, a perspectiva dos jogos coopetitivos oferece, portanto, para os pesquisadores de estratégia, quatro postulados principais para ajudá-los a ordenar o pensamento estratégico e entender as dinâmicas dos jogos entre atores, envolvendo, simultaneamente, conflito e cooperação.

O primeiro deles recomenda que para cada ação existe uma reação. Mas, ao contrário do que prediz a terceira lei de Newton, a reação, neste caso, nem sempre ocorre na mesma intensidade e em sentido contrário da ação que a causou. A fim de analisar como os outros jogadores irão reagir a seus movimentos, é necessário saber calcular e simular todas as reações (incluindo a sua própria) às 
ações empreendidas, com o máximo de antecedência possível. O segundo anuncia que é importante que cada jogador, ao interagir, desenvolva uma perspectiva alocêntrica - isto é, ter como foco os outros jogadores - com o objetivo de criar e capturar os seus valores. O princípio do alocentrismo enxerga os jogos de uma forma não egocêntrica, ou seja, os jogadores preocupando-se não apenas com sua própria posição. Para que se antevejam as posições futuras, raciocinando sobre as bases atuais, é preciso colocar-se no lugar das demais partes interessadas no jogo. Pensar como os outros jogadores.

O terceiro postulado da teoria dos jogos coopetitivos, por sua vez, prediz que não se pode retirar do jogo mais do que o total correspondente àquilo com que se contribui. Faz-se necessário, portanto, estimar corretamente o valor agregado gerado por cada um dos participantes do jogo. Cada jogador consegue alavancar seu valor agregado, à medida que analisa racionalmente e objetivamente duas questões capitais e complementares: Como cada jogador pode contribuir para agregar valor à minha posição? O que posso oferecer para eles? Dessa maneira é possível conciliar interesses e conduzir o jogo para a posição desejada.

O último postulado expressa a necessidade da identificação, por parte de cada jogador, dos elementos dos jogos, visando a influenciá-los. De acordo com esta abordagem teórica, cinco elementos principais caracterizam as interações nos jogos que envolvem, simultaneamente, conflito e cooperação: (1) escopos, que delimitam as fronteiras dos jogos; (2) regras, que definem o arcabouço regulatórioestrutural, que molda e é moldado pelos jogos; (3) jogadores, que identificam os atores envolvidos e as partes ativas dos jogos; (4) valores agregados, que correspondem às contribuições de cada ator aos jogos; (5) estratégias, que definem os movimentos escolhidos pelos atores durante a condução dos jogos. Influenciar o jogo, por meio de algum dos seus principais elementos, envolve a construção de um sistema de representação de interesses para a formação de estratégias de influência durante as interações da empresa com os stakeholders.

Assim, embora o pano de fundo conceitual da abordagem teórica dos jogos coopetitivos contribua para abordar a questão geral da configuração de uma coordenação coletiva a partir das ações estratégicas individuais, e determinar quais recursos devem ser mobilizados para a sua constituição, entre algumas de suas lacunas, dadas pela sua ótica, está a impossibilidade de responder, de maneira mais precisa e sistemática, à seguinte questão: Como negociar, por meio de uma rede de relacionamentos, a formação de estratégias coletivas, que levem em conta os interesses relevantes dos atores estratégicos envolvidos em específicas situações-problemas, e institucionalizar os acordos de cooperação, construídos a partir destes processos estratégicos coletivos, visando à legitimação das organizações no atual contexto ambiental? 
Essa parece ser a questão central da abordagem teórica dos stakeholders, embora privilegie as dimensões de planejamento e posicionamento do processo de formação de estratégias corporativas. Após constatar que, com a rápida ascensão dos relacionamentos cooperativos, a formação de estratégias deixa os limites exclusivos da organização isolada e se torna um processo conjunto a ser desenvolvido com parceiros, esta abordagem teórica parte dos pressupostos de que as organizações não operam no abstrato; não podem ser entendidas somente a partir do ponto de vista dos proprietários ou acionistas controladores (shareholders); e que o desenvolvimento de estratégias corporativas, relacionadas com o contexto ambiental, requer a interação das empresas com vários stakeholders que as influenciam ou são influenciados por elas.

Mostrando que a abordagem puramente técnico-econômica das organizações industriais apresenta insuficiências para descrever, analisar e compreender fenômenos contemporâneos como, por exemplo, o processo de formação de estratégias socioambientais corporativas, a abordagem teórica dos stakeholders propõe-se, então, a procurar resposta para algumas questões de cunho operacional: Qual o desenho da teia de influência dos stakeholders sobre a empresa? Qual o poder de influência desta teia sobre a empresa? Quais dos seus componentes devem ser levados em consideração no processo de formação de estratégias corporativas? Quais dos interesses e objetivos em jogo devem ser privilegiados para assegurar a sustentabilidade da empresa no longo prazo?

Assim, a abordagem teórica dos stakeholders, fundada por Freeman (apud Mitchell, Agle e Wood, 1997), bebendo nos pressupostos da teoria da firma, parte da premissa de que, em cenário complexo e instável, caracterizado pela descontinuidade e incerteza, a organização pode ser descrita e entendida como constelação de múltiplos interesses conflitivos e cooperativos (Donaldson e Preston, 1995). Este contexto controvertido coloca um desafio e releva uma nova dimensão para o processo de desenvolvimento de estratégias corporativas: a capacidade das empresas de relacionar-se, formar estratégias e firmar acordos satisfatórios com os vários stakeholders que contestam continuamente a sua legitimidade.

Assim, o processo de desenvolvimento de estratégias corporativas envolve a percepção e a identificação, por parte da empresa, dos stakeholders socioambientais (Winter, Lynn e Legerwood apud Polonsky, 1995a), pois a garantia de legitimidade da empresa passa pela necessidade de negociar decisões com estes jogadores, formular estratégias de influência e dar seqüência às questões e problemas socioambientais que integram a sua agenda, em cenário desafiador.

O processo estratégico socioambiental compreende, portanto, a gestão de um conjunto de relações da empresa com os stakeholders para a contínua renova- 
ção dos contratos sociais que assegurem a operação da empresa e apóiem a sua legitimidade diante da sociedade (Stainer e Stainer, 1998). Como o conjunto de relações da empresa com os stakeholders envolve tanto atores tradicionais quanto emergentes, um dos desafios colocado ao processo de desenvolvimento de estratégias socioambientais corporativas, diz respeito ao número e à heterogeneidade das interações em jogo.

Dado que o conjunto de stakeholders apresenta, freqüentemente, interesses e objetivos conflitivos, torna-se difícil a formação de estratégias socioambientais predominantemente cooperativas (Polonsky, 1995a, 1995b); portanto os conflitos de interesses que emergem das relações da empresa com os stakeholders e entre os próprios stakeholders, necessitam ser percebidos positivamente como demandas competitivas à procura da construção de mecanismos de coordenação que mesclem conflito-cooperação (Stainer e Stainer, 1998). Neste sentido, Freeman (apud Mitchell, Agle e Wood, 1997) e seguidores, como, por exemplo, Donaldson e Preston (1995), Polonsky (1995a, 1995b) e Stainer e Stainer (1998), consideram que o processo estratégico de gestão por stakeholders, embora com um viés normativo, é uma ferramenta analítica útil para a discussão de como os processos estratégicos são desenvolvidos nas empresas por meio das suas relações com os stakeholders.

Assim, elegeu-se, aqui, o processo estratégico de gestão por stakeholders, baseado em pressupostos que admitem a regulação do conflito, como mais um ponto de partida que, ao convergir para a abordagem teórica dos jogos coopetitivos, possa ajudar na compreensão do processo de formação das estratégias socioambientais corporativas.

Para Donaldson e Preston (1995) não obstante a abordagem dos stakeholders ter-se tornado lugar comum na literatura tanto acadêmica quanto profissional, o conceito que serve de base às várias definições de stakeholders é o de responsabilidade social corporativa. Esse ponto de vista é também corroborado por Stainer e Stainer (1998), uma vez que define a responsabilidade social corporativa como a obrigação que as organizações têm com as partes que influenciam ou que são influenciadas pelas políticas e decisões do seu negócio. Já Hill e Jones (1992) relacionam os conceitos de stakeholders e legitimidade, ao definir o primeiro como indivíduos ou grupos que possuem demandas consideradas legítimas pelas organizações. Carrol (apud Rowley, 1997) argumenta, entretanto, que grupos ou indivíduos podem ser considerados stakeholders em virtude das suas legitimidades; porém ele amplia o escopo do conceito ao incluir a noção de poder, relacionando-o com a capacidade daqueles de causar impacto nas organizações.

Uma das mais amplamente aceitas definições de stakeholder é baseada no princípio apresentado por Freeman (apud Mitchell, Agle e Wood, 1997), segundo 
o qual as organizações levam em conta, na formulação de seus propósitos, todos aqueles grupos ou indivíduos que as podem influenciar ou serem influenciados por elas. Assim, os stakeholders podem ser considerados como todas as partes interessadas nos rumos estratégicos da organização e que neles influem ou são por eles influenciados, devendo, por isto, ser considerados nos processos de tomada de decisão. Dentro desta definição pode-se identificar tanto stakeholders tradicionais (clientes, fornecedores, acionistas, competidores etc.) quanto emergentes (agências governamentais, organizações sociais, agências de regulação, Organizações Não Governamentais - ONGs, associações de populações tradicionais, associações comunitárias locais etc.).

Para Mintzberg, Ahlstrand e Lampel (2000) a abordagem teórica dos stakeholders pode ser apreendida como tentativa de lidar com as forças políticas por meio de uma lente racional- voluntarista, ou seja, é a solução da escola do planejamento estratégico à complexidade e aparente confusão do processo político-institucional de construção de mecanismos de coordenação coletiva não-mercantis. Desse modo, para os adeptos da abordagem teórica dos stakeholders, uma estratégia de legitimação é a ferramenta que permitirá que a empresa oriente seus objetivos de rentabilidade e crescimento, diante de seus diversos stakeholders, coerente com as necessidades do mercado e em consonância com os padrões de responsabilidade social e ambiental. Por meio desta estratégia a organização responde às pressões e aspirações dos demais stakeholders, ao mesmo tempo que representa e defende a consecução de seus próprios interesses.

Utilizando-se da grade de leitura, construída a partir das premissas das abordagens teóricas dos jogos coopetitivos e stakeholders, discutidas neste item, passa-se, a seguir, à apresentação do perfil corporativo da Aracruz Celulose e à análise das interações da Aracruz Celulose com os stakeholders durante o processo de formação de estratégias socioambientais corporativas.

\section{Aracruz Celulose S.A.: Perfil Corporativo}

A Aracruz Celulose S.A. é a maior produtora mundial de celulose de fibra curta de eucalipto, com uma capacidade de produção de 1.200.000 toneladas por ano, suprindo, aproximadamente, $22 \%$ da demanda mundial de celulose de eucalipto e cerca de 7\% de celulose de fibra curta (Aracruz Celulose, 2000). A empresa caracteriza-se por ser altamente intensiva em capital, fabricar uma commodity global e concorrer em um mercado cíclico. Uma das principais estratégias concorrenciais da empresa é a liderança de custo de produção, apoiada principalmente no baixo custo de produção da madeira obtida por meio da implantação de 
tecnologia florestal de ponta (Citicorp, 1998). O controle da Aracruz é exercido por quatro acionistas: o grupo norueguês Lorentzen (28\%), o sul-africano Mondi (28\%), o brasileiro Safra (28\%) e o Banco Nacional de Desenvolvimento Econômico e Social - BNDES (12,5\%). A empresa opera de forma integrada, segundo um sistema baseado no trinômio florestas-fábricas-porto, ocupando uma área territorial de 203.000 ha e gerando cerca de 5.000 empregos diretos e indiretos (Aracruz Celulose, 2000). A base florestal da empresa espalha-se pelo norte do Espírito Santo e extremo sul da Bahia, enquanto a fábrica e o porto estão situados no município de Aracruz (ES).

\section{Aracruz Celulose: Múltiplos Jogos Empresa-Stakeholders e Múltiplas Estratégias de Influência}

Confrontada com a pressão de stakeholders, tais como agências governamentais, por meio da regulamentação e da fiscalização; concorrentes e instituições de representação de interesses, por meio da cristalização de certas regras de convivência e competição, como as certificações ambientais; a própria sociedade (ONGs, comunidades locais etc.), mediante a demanda por informações sobre desempenho socioambiental e exigência de atuação criteriosa da empresa no que diz respeito aos padrões de sustentabilidade ambiental e social, a Aracruz desenvolve estratégias socioambientais de influência a partir de interações com esses stakeholders.

Desenvolver estratégias para influenciar os jogos empresa-stakeholders, parece ser o processo dominante na Aracruz para a formação de estratégias socioambientais corporativas. Para a Aracruz, influenciar é representar interesses, por meio da organização de sistemas articulados de representação; é tentar moldar as reações dos outros jogadores, o que só é possível com a formação de estratégias corporativas e ações coordenadas, envolvendo a conformação de jogos empresa-stakeholders.

Denominada no Relatório Anual da Aracruz Celulose (2000, p. 26), na seção dedicada ao Balanço Social e Ambiental, de "contribuição ao esforço comum” e definida formalmente como "a participação no desenvolvimento de programas, políticas e legislações que concorram para o desenvolvimento sustentável”, a ação coordenada do processo de formação de estratégias de influência da Aracruz envolve um sistema de representação de interesse internacional, nacional e estadual, cujas instituições mais importantes e respectivas posições ocupadas pela empresa são mostradas no Quadro 1. 


\section{Quadro 1: Aracruz Celulose - Sistema de Representação de Interesses Socioambientais}

\begin{tabular}{|c|c|c|c|}
\hline Âmbito & Instituição & Fórum & Posição \\
\hline \multirow[t]{2}{*}{ Internacional } & WBCSD & Comitê Executivo & Membro Efetivo \\
\hline & IFIR & $\begin{array}{l}\text { Grupo de Trabalho de Reconhecimento Mútuo } \\
\text { dos Sistemas de Certificação Florestal }\end{array}$ & $\begin{array}{l}\text { Membro Efetivo } \\
\text { (representante da } \\
\text { BRACELPA) }\end{array}$ \\
\hline \multirow[t]{7}{*}{ Nacional } & CEBDS & $\begin{array}{l}\text { Conselho de Administração, Diretoria e Câmara } \\
\text { Técnica de Legislação }\end{array}$ & $\begin{array}{l}\text { Presidência de Honra, } \\
\text { Membro Efetivo e } \\
\text { Coordenador }\end{array}$ \\
\hline & BRACELPA & $\begin{array}{l}\text { Conselho de Administração, Conselho } \\
\text { Deliberativo e Grupo de Trabalho de } \\
\text { Certificação }\end{array}$ & $\begin{array}{l}\text { Vice-Presidência, } \\
\text { Membro Eleito e } \\
\text { Coordenação }\end{array}$ \\
\hline & SBS & $\begin{array}{l}\text { Câmara Técnica sobre Política e Legislação } \\
\text { Florestal }\end{array}$ & Membro Efetivo \\
\hline & $\mathrm{CNI}$ & $\begin{array}{l}\text { Conselho Temático Permanente de Meio } \\
\text { Ambiente e Grupo de Trabalho de Legislação } \\
\text { Ambiental }\end{array}$ & $\begin{array}{l}\text { Membro Efetivo e } \\
\text { Coordenação }\end{array}$ \\
\hline & CONAMA & $\begin{array}{l}\text { Subgrupo de Trabalho da Câmara Técnica } \\
\text { sobre Licenciamento Ambiental }\end{array}$ & Membro Efetivo \\
\hline & FSC & $\begin{array}{l}\text { Câmara Empresarial e Subgrupo de Trabalho } \\
\text { sobre Padrões de Certificação para Plantações } \\
\text { Florestais }\end{array}$ & $\begin{array}{l}\text { Membro Efetivo } \\
\text { juntamente com o } \\
\text { representante da SBS }\end{array}$ \\
\hline & FBDS & Conselho de Curadores & Membro Efetivo \\
\hline \multirow[t]{2}{*}{ Estadual } & FINDES & $\begin{array}{l}\text { Conselho Econômico e Conselho de Meio } \\
\text { Ambiente }\end{array}$ & $\begin{array}{l}\text { Presidência e } \\
\text { Coordenação }\end{array}$ \\
\hline & CONSEMA & Grupo de Trabalho de Legislação Ambiental & $\begin{array}{l}\text { Coordenação e Membro } \\
\text { Efetivo }\end{array}$ \\
\hline
\end{tabular}

Fonte: adaptado de Andrade (2000).

Em alguns jogos, há a participação de mais de uma instituição de representação, além de um contínuo processo de concertação de interesses e negociação de acordos prévios entre os diversos segmentos do complexo. Os principais jogos socioambientais entre Aracruz-stakeholders são apresentados no Quadro 2 e analisados nos três tópicos a seguir, utilizando-se as categorias de análise abaixo.

- Tipos de Demanda. Identificam os escopos dos jogos. Foram identicados na Aracruz três escopos que delimitam as fronteiras dos espaços, onde ocorrem as interações da empresa com os stakeholders socioambientais: de mercado, regulatório e de comunicação. Os escopos dos jogos são definidos, previamente, em função do tipo de demandas, naturais ou induzidas, provenientes dos stakeholders socioambientais.

- Vetores de Demanda. São os tipos de demandas socioambientais traduzidos em regras e levados à esfera de percepção da Aracruz. São eles que providen- 
ciam a estrutura e o alicerce regulatório prévios sobre os quais se construirão os jogos. Há, portanto, uma relação íntima entre os escopos dos jogos e os vetores de demanda socioambientais da Aracruz.

- Stakeholders. São os jogadores ou atores socioambientais que participam dos múltiplos jogos disputados pela Aracruz. Eles são continuamente monitorados e identificados quanto à forma de participação, número, papel, objetivos e poder de influência, com a finalidade de aumentar as possibilidades de barganha por parte da empresa.

- Objetivos. Correspondem aos valores que cada jogador agrega ou com os quais contribui para os jogos. Com o intuito de aumentar o seu valor agregado perante stakeholders, a Aracruz tenta analisar a sua "razão preferencial de ser", estima as "razões prováveis de ser" dos demais participantes e utiliza-se de estratégias de influência com o intuito de diminuir esta distância.

. Estratégias. São os movimentos, ou opções de movimentos, com componentes simultâneos de conflito e cooperação utilizados pela Aracruz, para influenciar a maneira pela qual os stakeholders percebem e conduzem o jogo.

As informações e dados que serviram de base para a elaboração dos próximos três tópicos foram obtidas, principalmente, junto às seguintes fontes: Aracruz Celulose (1995, 1996, 1998, 1999, 2000) e Roxo (1995, 1996, 1997, 1998, 1999). 


\section{Quadro 2: Aracruz Celulose S.A. - Jogos Socioambientais}

\begin{tabular}{|c|c|c|c|c|c|}
\hline \multicolumn{4}{|c|}{ DEMANDAS SOCIOAMBIENTAIS } & \multicolumn{2}{|c|}{ JOGOS } \\
\hline TIPO & VETORES & EXEMPLOS & STAKEHOLDERS & OBJETIVOS & ESTRATÉGIAS \\
\hline Mercado & $\begin{array}{l}\text { Sistemas de } \\
\text { certificação } \\
\text { florestal, } \\
\text { ambiental e } \\
\text { de produto. }\end{array}$ & $\begin{array}{l}\text { FSC } \\
\text { ISO 14001- } \\
\text { MFS/ TR14061 } \\
\text { PEFC } \\
\text {. ISO 14001 } \\
\text { Selo Verde da } \\
\text { Comunidade } \\
\text { Européia } \\
\text { Ecotaxas }\end{array}$ & $\begin{array}{r}\text { BRACELPA, SBS, } \\
\text { IFIR, } \\
\text { WBCSD,CEBDS e } \\
\text { CB-38. }\end{array}$ & $\begin{array}{r}\text { Manter } \\
\text { vantagem } \\
\text { competitiva } \\
\text { pela } \\
\text { diminuição de } \\
\text { custos de } \\
\text { produção e } \\
\text { evitar barreiras } \\
\text { alfandegárias. } \\
\text { Transformar } \\
\text { questões } \\
\text { socioambien- } \\
\text { tais em } \\
\text { barreiras } \\
\text { técnicas prote- } \\
\text { cionistas. }\end{array}$ & $\begin{array}{l}\text { Influenciar o } \\
\text { desenvolvimento } \\
\text { de sistemas de } \\
\text { certificação } \\
\text { considerados } \\
\text { demandas } \\
\text { efetivas de } \\
\text { mercado. } \\
\text { Estar preparado } \\
\text { para certificação } \\
\text { quando existirem } \\
\text { demandas } \\
\text { efetivas. }\end{array}$ \\
\hline Regulação & $\begin{array}{l}\text { Convenções } \\
\text { internacionais } \\
\text { e legislações } \\
\text { ambientais } \\
\text { federais e } \\
\text { estaduais. }\end{array}$ & $\begin{array}{l}\text { Mudança do } \\
\text { Clima, Biodi- } \\
\text { versidade e } \\
\text { Espécies em } \\
\text { Extinção. } \\
\text { Consolidação } \\
\text { da Legislação } \\
\text { Ambiental } \\
\text { Nacional. } \\
\text { Política } \\
\text { Estadual de } \\
\text { Recursos } \\
\text { Hídricos e } \\
\text { Normalização } \\
\text { da Qualidade } \\
\text { da Água. }\end{array}$ & $\begin{array}{r}\text { FBDS, } \\
\text { BRACELPA, } \\
\text { FINDES, } \\
\text { CNI, SBS, } \\
\text { WBCSD, CEBDS e } \\
\text { IFIR. }\end{array}$ & $\begin{array}{r}\text { Prevenir } \\
\text { aumentos } \\
\text { substanciais de } \\
\text { custos no ciclo } \\
\text { de produção } \\
\text { de celulose. } \\
\\
\\
\text { Tentar ampliar } \\
\text { e introduzir } \\
\text { princípios e } \\
\text { padrões } \\
\text { ambientais } \\
\text { cada vez mais } \\
\text { restritivos. }\end{array}$ & $\begin{array}{l}\text { Influenciar o } \\
\text { desenvolvimento } \\
\text { de tratados, } \\
\text { convenções e } \\
\text { legislações- } \\
\text { chaves. } \\
\\
\text { Conseguir as } \\
\text { licenças } \\
\text { ambientais e } \\
\text { procurar cumprir } \\
\text { além da legislação } \\
\text { ambiental ao } \\
\text { menor custo } \\
\text { possível. }\end{array}$ \\
\hline Comunicação & $\begin{array}{l}\text { Informações e } \\
\text { verificações } \\
\text { de uma } \\
\text { terceira parte } \\
\text { sobre } \\
\text { sustentabili- } \\
\text { dade da } \\
\text { produção de } \\
\text { celulose e } \\
\text { desempenho } \\
\text { socioambi- } \\
\text { ental da } \\
\text { empresa. }\end{array}$ & $\begin{array}{l}\text { Balanço Social e } \\
\text { Ambiental, } \\
\text { Auditorias, } \\
\text { Questionários e } \\
\text { Projetos } \\
\text { Socioambientais } \\
\text { Cooperativos. }\end{array}$ & $\begin{array}{l}\text { CPT, IPEF, SIF, } \\
\text { CTCP, WBCSD, } \\
\text { CEBDS, IUFRO, } \\
\text { SBS, IIED, } \\
\text { EMBRAPA e } \\
\text { EMCAPER. } \\
\\
\text { Consumidores, } \\
\text { clientes, FASE, } \\
\text { IBASE, CDDH, } \\
\text { CEPEDES, CIMI } \\
\text { e NISI. }\end{array}$ & $\begin{array}{l}\begin{array}{r}\text { Conquistar } \\
\text { credibilidade } \\
\text { ambiental e } \\
\text { eliminar } \\
\text { paternalismo } \\
\text { social. } \\
\\
\text { Tentar } \\
\text { monitorar e } \\
\text { exigir da } \\
\text { empresa maior } \\
\text { responsabilida- } \\
\text { de ambiental e } \\
\text { social. }\end{array} \\
\end{array}$ & $\begin{array}{l}\text { Fortalecer a } \\
\text { imagem } \\
\text { corporativa de } \\
\text { responsabilidade } \\
\text { socioambiental. } \\
\\
\text { Evitar a prática } \\
\text { de doações e } \\
\text { patrocínios } \\
\text { assistencialistas. }\end{array}$ \\
\hline
\end{tabular}

Fonte: adaptado de Andrade (2000). 


\section{Jogos de Mercado: Obter Vantagem Competitiva versus Manter Vantagem Competitiva}

Quanto às demandas de mercado, a Aracruz participa de vários jogos responsáveis pelo desenvolvimento e consolidação de vetores de demanda autoregulatórios, que podem causar impacto na dinâmica competitiva da empresa. Estes jogos, sumariados no Quadro 2, envolvem o desenvolvimento de sistemas de certificações ambientais e podem ser classificados em quatro categorias: certificações florestais (FSC/TR 14061/PEFC), que exercem forte impacto sobre os processos de manejo e desempenho florestal da empresa; certificações ambientais (ISO 14001) relacionadas à normatização de Sistemas de Gestão Ambiental; certificações de produto (Selo Verde da Comunidade Européia para produtos de papéis sanitários) e instrumentos econômicos (Ecotaxas).

Estes vetores são demandados, principalmente, pelos stakeholders (FSC, WWF, WG2/TC-207 e CE, respectivamente) que, segundo a percepção da Aracruz, têm como objetivo procurar obter vantagem competitiva pela exploração de questões ambiental e social. A Aracruz fundamenta essa sua percepção em pesquisas realizadas com clientes no exterior, que demostraram ser a preocupação com o meio ambiente o quarto fator de decisão de compra e de influência futura no mercado.

Por outro lado, a Aracruz desenvolve estratégias de influência, tendo como objetivos evitar que esses jogos afetem significativamente a sua principal vantagem competitiva, assentada no baixo custo de produção de madeira, e desenvolvam barreiras não-tarifárias ao comércio de celulose, que possam reduzir suas vendas. Para isto ela lança mão de movimentos estratégicos: um ofensivo (influenciar os principais atores responsáveis pelo desenvolvimento de sistemas de certificação ambiental passíveis de se transformarem em demandas de mercado); e outro defensivo (estar preparada para obter as certificações tão logo o mercado de celulose as demande).

Tentando evitar a transformação de questões técnicas em disputas políticas, a Aracruz tenta influenciar os jogos socioambientais de mercado, trazendo para o jogo outros jogadores que podem representar seus interesses, mediante esforço coordenado de construção de base política favorável às discussões técnicas. Cada jogador tem o seu papel: o WBCSD - por meio do seu Grupo Florestal - dialoga com o FSC Internacional; a ABNT/CB-38 representa os interesses do Brasil no processo de desenvolvimento e revisão da série ISO 14000 junto aos subcomitês do TC-207; a SBS é responsável pelo desenvolvimento do selo verde nacional de Certificação Florestal (CERFLOR). A própria Aracruz exerce a liderança junto à FSC Brasil, representando os interesses da BRACELPA, e acompanha os 
processos de desenvolvimento da série ISO 14000, TR 14061 e Selo Verde da Comunidade Européia, por meio da coordenação do Grupo de Trabalho de Certificação da BRACELPA.

\section{Jogos de Regulação: Ampliar Padrões Ambientais versus Evitar Custos Adicionais}

No que diz respeito às demandas por regulação das questões socioambientais, a Aracruz participa de jogos que envolvem vetores de demandas socioambientais de caráter voluntário e/ou mandatório. Esses jogos, sumariados no Quadro 2, apresentam três níveis de escopo: internacional (Agenda 21 e Convenções e Tratados sobre Mudanças Climáticas, Florestas, Biodiversidade e Espécies em Extinção); nacional (Consolidação da Legislação Ambiental, Nova Lei de Recursos Hídricos e Agência de Bacias Hidrográficas, Revisão da Política Florestal, Revisões do Sistema de Licenciamento Ambiental, das Legislações sobre Auditorias e Impactos Ambientais); estadual (Reformulação do CONSEMA, Política Estadual de Recursos Hídricos, Desenvolvimento dos Códigos Florestais e de Meio Ambiente do Espírito Santo e Normalização da Qualidade da Água). Os objetivos desses jogos são muito similares, independentemente do escopo onde eles são disputados.

Enquanto o IPF, CONAMA, SEAMA, CONSEMA, CRA e CEPRAM procuram ampliar e introduzir princípios e padrões ambientais mais restritivos, a Aracruz tenta influenciá-los por meio da organização de um sistema de representação de interesses formado, em âmbito internacional, pelo WBCSD e IFIR; nacional, pela BRACELPA, FBDS, CEBDS e CNI; e estadual, pela FINDES (vide Quadro 1). O objetivo da Aracruz nesses jogos é tentar evitar que as restrições advindas das políticas públicas ambientais venham a significar custos adicionais significativos em todo o ciclo de produção de celulose de mercado. As opções de movimentos pendulares utilizadas pela empresa durante os jogos regulatórios mesclam conflito e cooperação: por um lado, tentam influenciar o desenvolvimento dos principais vetores de demandas socioambientais, voluntários e/ou compulsórios, para conseguir as licenças ambientais das agências públicas de regulação, pelo menor custo possível; por outro, procura cumprir além do que lhe é exigido pelas legislações ambientais.

Coordenando fóruns institucionais ou deles participando (como, por exemplo, o Conselho de Meio Ambiente da FINDES, o Grupo de Trabalho de Legislação Ambiental da CNI etc.), que têm como objetivos acompanhar e analisar a legislação ambiental e florestal brasileira; discutir os impactos das políticas públicas e do desenvolvimento da legislação sobre a competitividade das empresas; identificar tópicos legislativos que carecem de fundamentação técnico-científica e ela- 
borar propostas para a revisão e/ou aprimoramento da legislação, a Aracruz conquista espaço político para se manisfestar e defender o seu ponto de vista e sobretudo influenciar o processo de consolidação da legislação ambiental e florestal brasileira.

\section{Jogos de Comunicação: Exigir Responsabilidade Socioambiental versus Construir Imagem Institucional Positiva}

Os jogos de comunicação, sumariados no Quadro 2, são aqueles que se desenrolam em torno de demandas resultantes da complexificação do espaço social. Clientes, consumidores, ONGs (como a FASE, IBASE, CDDH e CEPEDES), populações tradicionais (representadas pelo NISI e CIMI), movimentos comunitários e demais atores socioambientais exigem informações, verificações e ações concretas referentes ao desempenho ambiental e social da Aracruz. Informações sobre emissões hídricas e atmosféricas, auditorias ambientais periódicas, relatórios ambientais, balanços sociais, projetos socioambientais, entre outras, são os principais vetores de demandas deste tipo de jogo. Para os atores socioambientais, trata-se de procurar verificar e aumentar a responsabilidade ambiental e social da empresa, em função do bem-estar coletivo.

Para a Aracruz, o objetivo dos jogos de comunicação é conquistar credibilidade ambiental e eliminar o paternalismo social. Segundo a empresa, isso é mais do que simples prestação de contas da eqüidade de suas atividades perante o público interessado; significa a renovação contínua, por meio do processo de negociação permanente com os atores socioambientais, do contrato social que permite a sua operação e lhe concede legitimidade.

Assim, enquanto, por um lado, a empresa urde estratégias de fortalecimento da sua imagem corporativa, associada à responsabilidade ambiental e social, por meio do desenvolvimento de projetos cooperativos com stakeholders que possam agregar valor à sua imagem pela construção de uma agenda socioambiental positiva, por outro, tece os fios para a confecção de uma rede estratégica formada por uma malha que tente eliminar a visão paternalista desses mesmos stakeholders para com a empresa. Essas estratégias têm dois focos principais: desmitificar a não-sustentabilidade da eucaliptocultura como fator de desenvolvimento regional e inserir de maneira mais adequada na realidade empresarial as chamadas social issues.

No que diz respeito ao primeiro foco, uma das estratégias socioambientais da Aracruz para fazer face ao problema denominado pela empresa como "mito da não-sustentabilidade" das plantações de eucalipto, foi a construção de uma rede de jogadores (formada pelo CPT, IPEF, SIF, CTCP, IUFRO, EMBRAPA, entre 
outros) para suprir e difundir informações “científicas e consistentes” sobre a sustentabilidade do processo de produção de celulose de eucalipto, que servisse de subsídio ao processo decisório da empresa e consolidasse uma imagem institucional, pautada na confiança, num cenário desenhado por "muitos mitos e poucos fatos”.

Quanto ao segundo foco, referente ao tratamento dado às questões sociais, a Aracruz desenvolve projetos socioambientais em parcerias com stakeholders locais, nacionais e internacionais: EMCAPER, SBS, CEBDS, WBCSD, IIED etc. Esses projetos cooperativos estão associados à estratégia de vincular a sua imagem institucional e ação social ao conceito de responsabilidade social corporativa. Elegendo como prioridade a educação, o objetivo da Aracruz é tentar acabar com a tradicional política de doações, que estaria identificada com padrões paternalistas e ineficazes de assistência social. No entanto, ao enfrentar esse desafio, a Aracruz tenta deixar claro como percebe o problema associado ao processo de incorporação das social issues e os limites quase sempre nebulosos entre o seu papel, como empresa privada, e o dos poderes públicos.

Uma das peças que compõem a estratégia da empresa, neste tipo de jogo, é atrelar a gestão das questões socioambientais às ações programáticas de comunicação e relações institucionais, com o objetivo de manter os stakeholders continuamente informados, de maneira proativa e consistente, sobre as atividades e as posições da empresa em questões controvertidas que podem afetar a sua imagem e competitividade. Este movimento estratégico da Aracruz, baseado no binômio conflito-cooperação, envolve a busca de maior legitimidade perante a sociedade, por meio de um processo contínuo de mudança da dupla visão paternalista vinculada à ação social - tanto a sua quanto a da comunidade da área de influência - durante os jogos de comunicação.

Para fazer isso, a empresa, na medida do possível, tenta trazer para os jogos de comunicação os stakeholders que compartilhem dessa mesma percepção. Visando assegurar resultados efetivos, com relação à melhoria de imagem e relações empresa-stakeholders, e eliminar as doações e patrocínios paternalistas, fragmentados, do tipo toma-lá-da-cá, decididos caso a caso de forma reativa, a Aracruz tenta claramente delimitar e concentrar os seus recursos disponíveis em projetos específicos, selecionados segundo os seguintes padrões: nível de coerência com os objetivos corporativos da empresa; grau futuro de eficácia e sustentabilidade dos projetos propostos; experiência comprovada da entidade gestora do projeto na área em exame; ou seja, na medida do possível, os parceiros são selecionados e autorizados a participar dos jogos de comunicação de cunho socioambiental. 


\section{Considerações Finais e Recomendações}

Este trabalho teve por objetivo analisar as interações da Aracruz com os stakeholders, em torno de demandas de mercado, de regulação e de comunicação, durante o processo de formação de estratégias socioambientais corporativas. Ao longo do trabalho, tais relações entre a Aracruz e seus stakeholders foram apresentadas e analisadas à luz de uma grade analítica, construída a partir de premissas teóricas das abordagens dos jogos coopetitivos e stakeholders. Constatou-se, porém, que esta grade analítica, quando aplicada ao caso específico da Aracruz Celulose, contribuiu para a identificação e classificação dos múltiplos jogos empresa-stakeholders, necessários à apresentação e análise do processo de formação das estratégias socioambientais corporativas. Dessa maneira, argumenta-se que para administrar a tensão inerente aos seus interesses corporativos e àqueles dos stakeholders, a Aracruz identifica os elementos mais importantes dos jogos socioambientais nos quais está envolvida, e formula estratégias para influenciá-los por meio do planejamento de um sistema de representação e defesa dos seus interesses.

Ainda assim, convém salientar que, com sua enfâse no intercâmbio racional como locus de formação de estratégias, visando à prescrição de posições ótimas para as empresas, a grade analítica aqui utilizada privilegiou a compreensão da face deliberada e formal do processo de formação de estratégias socioambientais. Observou-se que este processo é muito mais rico, multifacetado, confuso e dinâmico que aquele, ordenado e estático, apresentado e analisado pelas abordagens teóricas dos jogos coopetitivos e stakeholders. Assim, defende-se que o seu papel é mais de apoiar o processo de formação de estratégias organizacionais do que de sê-lo.

Não se trata de negar, aqui, a perspectiva racionalista-voluntarista, pautada na maximização e racionalização, mas de alertar para a sua insuficiência. Assim, como a preocupação exagerada com a maximização dos resultados individuais, ignorando-se os interesses das outras partes no jogo, pode gerar conflitos socioambientais ainda maiores e ser prejudicial ao interesse coletivo, colocando um dilema para a interação da empresa com os stakeholders, a compreensão do processo de construção de ações coletivas, a partir de comportamentos individuais dos atores envolvidos em conflito, parece especialmente adequada à análise de situações-problemas relacionadas com o processo de formação de estratégias socioambientais para gerir bens públicos de uso comum.

Ressalta-se, porém, que um entendimento ampliado do processo de formação de estratégias socioambientais corporativas poderia ser obtido à medida que este 
fenômeno pudesse ter sido analisado de maneira concomitante com o contexto no qual está localizado; e as interações estratégicas da empresa com os stakeholders poderiam também ser definidas por meio do esclarecimento dos seus contornos político-institucionais, e não somente pelas suas fronteiras racional-voluntaristas.

Assim, nesta linha de argumentação, aponta-se, a seguir, as limitações deste trabalho que permitiram a extração de lições para futuras investigações sobre 0 objeto aqui estudado.

. Embora o trabalho agregue evidências empíricas e teóricas para o planejamento do processo de formação das estratégias socioambientais corporativas, é difícil imaginar como as organizações poderiam identificar, analisar e controlar, a priori, quem tem influência sobre elas e responder de maneira ordenada para equilibrar essas pressões, sem levar em consideração, contudo, as situações específicas de interação estratégica nas quais estão envolvidas e as incertezas que lhe são características. Em outras palavras: é possível desenvolver, $a$ priori, um processo de planejamento estratégico que preserve a legitimidade da empresa, reduza a sua vulnerabilidade a choques externos causados por stakeholders insatisfeitos e conseqüentemente conquiste vantagens competitivas resultantes de uma melhor relação com os seus stakeholders?

- A insuficiência de grades analíticas que enfatizam o comportamento de atores racionais, que agem em interesses próprios e ordenam com coerência dedutiva todas as possibilidades ao fazerem opções estratégicas. O pressuposto da racionalidade ilimitada facilita a apresentação e a análise dos processos estratégicos, fazendo com que seja fácil compreender a sua dimensão racionalvoluntarista. Assim, um dos limites mais restritivos deste trabalho parece ser a dificuldade, à luz da grade analítica construída, de uma representação ampliada do processo de formação de estratégias socioambientais na sua dimensão político-institucional, tendo como premissa básica a racionalidade limitada e indutiva dos atores estratégicos.

. Os limites deste trabalho para explicar a realidade de uma forma mais encarnarda, localizando as situações-problemas no contexto político-institucional responsável pelas suas formas, significados e conteúdos. Ao admitir que os atores apresentam certa autonomia relativa em relação ao outro e ao contexto da situação na qual está envolvido, a grade analítica utilizada não privilegia o contexto e os problemas macropolíticos e institucionais, como se os conflitos empresa-stakeholders pudessem ser resolvidos exclusivamente no âmbito da racionalidade ilimitada do homem técnico-econômico. Assim, surge a necessidade de contextualizar o conceito de stakeholder num espaço macro, caracterizado pela existência de uma arena política, onde ocorre o enfrentamento de 
atores sociais para a construção de estratégias socioambientais, sobretudo por meio de um exercício político e de jogos de poder.

- A importância de lançar mão de mecanismos institucionais de coordenação não-mercantis, que possam oferecer, de maneira assimétrica, elementos contextuais aos atores estratégicos. Assim, contrariando a lógica da racionalidade ilimitada, segundo a qual os atores não partilham nada a não ser os seus desejos de maximizar os seus interesses pessoais, faz-se necessário analisar como os jogadores têm acesso a dados contextuais comuns, que permitem a construção de referências coletivas como soluções possíveis para os jogos estratégicos socioambientais.

Feitas essas considerações a respeito dos alcances e limites deste trabalho de pesquisa, recomenda-se, por fim, como forma de contribuir para o processo acumulativo de construção do conhecimento e para uma compreensão ampliada dos fenômenos organizacionais, que a análise das interações estratégicas da empresa com os stakeholders aqui realizada, seja feita com a colaboração teórica da perspectiva político-institucional. Segundo esta abordagem, a ação coletiva ou os mecanismos de coordenação, construídos a partir das interações da empresa com os stakeholders, moldurada por regras, normas e convenções institucionalizadas, é também, além do intercâmbio racional entre os atores, um dos importantes agentes desencadeadores dos processos estratégicos. Assim, ter-se-ia uma análise das relações empresa-stakeholders sob um foco mais ampliado de luz, além do ângulo racional-voluntarista com que ela é predominantemente iluminada pela literatura e estado de campo sobre processo de formação de estratégias corporativas.

\section{RefERÊNCIAS Biblográficas}

ANDRADE, J. C. S.

Conflito, cooperação e convenções: a dimensão políticoinstitucional das estratégias socioambientais da Aracruz celulose (1990-1999). Salvador, 2000. Tese (Doutorado em Administração) - Núcleo de Pós-Graduação em Administração, Universidade Federal da Bahia.
ARACRUZ CELULOSE. International relations programme. Rio de Janeiro, 1995.

Annual report. Rio de Janeiro, 1996.

Atuação social da Aracruz Celulose (1995-1997). Vitória, 1998. 
Plano de melhorias ambientais para 1999. Rio de Janeiro, 1999.

Relatório anual - 1999: balanço social e ambiental. Rio de Janeiro, 2000.

BRANDENBURGER, A. M.;

NALEBUFF, B.

The right game: use game theory to shape strategy. Harvard Business Review, p. 57-71, July/ Aug. 1995.

\section{CITICORP SECURITIES.}

Brazilian pulp and paper industry. New York: Aracruz Celulose S.A., July 1998. p. 34-42.

DIXIT, A. K.;

NALEBUFF, B. J.

Pensando estrategicamente. São Paulo: Atlas, 1994.

DONALDSON, T.;

PRESTON, L. E.

The stakeholder theory of the corporation: concepts, evidence, implications. Academy of Management Review, v. 20, n. 1, p. 65-91, 1995.

\section{LECOMTE, J.}

Conflit et coopération: la théorie des jeux. Sciences Humaines, $n$. 82, avr. 1998.

MILANI, C. R. S.

L'environnement: quelles régulations de l'ordre mondial? Paris : UNESCO, jan. 1998.
MINTZBERG, H.;

LAMPEL, J.;

AHLSTRAND, B.

Safári de estratégia. Porto

Alegre: Bookman, 2000.

MITCHELL, R. K.;

AGLE, B. R.;

WOOD, D. J.

Towards a theory of stakeholder identification and salience: defining the principle of who and what really counts. Academy of Management Review, v. 22, n. 4, p. 853-886, 1997.

POLANSKY, M. J.

Incorporating the natural environment in corporate strategy: a stakeholder approach. The Journal of Business Strategies, v. 12, n. 2, p. 151-168, 1995a.

A stakeholder theory approach to designing environmental marketing strategy. Journal of Business \& Industrial Marketing, v. 10, n. 3, p. 29-46, 1995b.

ROTHSCHILD, R.

Ten simple lessons in strategy from the games firms play: how some business decisions can be analysed as games. Management Decision, v. 33, n. 9, p. 24-29, 1995. 
ROWLEY, T. J.

Moving beyond dyadic ties: a network theory of stakeholder influences. Academy of Management Review, v. 22, n. 4, p. 887-910, Oct. 1997.

ROXO, C. A.

Condicionamentos ambientais à indústria de celulose. In: SEMINÁRIO INTERNO DA CAEMI: ISO 14000 E O PLANO DIRETOR DE MEIO AMBIENTE, 1995, Rio de Janeiro. Anais... Rio de Janeiro: [s.n.], 1995.

Demandas ambientais externas: perspectivas e estratégias de influência. Rio de Janeiro: Aracruz Celulose, 1996.

Análise sobre o papel das entidades de classe na área de meio ambiente. Rio de Janeiro: Aracruz, 1997.

Posição da Aracruz em relação à certificação. In: SEMINÁRIO SOBRE CERTIFICAÇÃO AMBIENTAL VERSUS
CERTIFICAÇÃO FLORESTAL: TENDÊNCIAS E EXPECTATIVAS A NÍVEL NACIONAL E INTERNACIONAL, 1998, São Paulo. Anais... São Paulo: SBS, 1998.

Forestry certification as a market instrument - latest developments and challenges ahead. In: FAO ADVISORY COMMITTEE ON PAPER AND WOOD PRODUCTS, 1999, São Paulo. Anais... São Paulo: FAO, 1999.

SIMONSEN, M. H.

O que emperra o país na busca pela eficiência. Exame. São Paulo: Editora Abril, p. 16-17, abr. 1997. Edição especial.

STAINER, A.;

STAINER, L.

Business performance: a stakeholder approach.

International Journal of Business Performance Management, v. 1, n. 1, p. 2-12, 1998. 


\section{Lista de Siglas}

BRACELPA - Associação Brasileira de Celulose e Papel.

CB 38 - Comitê Brasileiro para Meio Ambiente da Associação Brasileira de Normas Técnicas (ABNT).

CDDH - Centro de Defesa dos Direitos Humanos.

CEBDS - Conselho Empresarial Brasileiro para o Desenvolvimento Sustentável. CE - Comunidade Européia.

CEPEDES - Centro de Estudos e Pesquisas para o Desenvolvimento do Extremo Sul da Bahia.

CEPRAM - Conselho Estadual de Meio Ambiente do Estado da Bahia.

CIMI - Conselho Indigenista Missionário.

CNI - Confederação Nacional da Indústria.

CONAMA - Conselho Nacional de Meio Ambiente.

CONSEMA - Conselho Estadual de Meio Ambiente do Estado do Espírito Santo.

CPT - Centro de Pesquisas Tecnológicas da Aracruz Celulose S.A.

CRA - Centro de Recursos Ambientais do Estado da Bahia.

CTCP - Centro Técnico de Celulose e Papel.

EMBRAPA - Empresa Brasileira de Pesquisa Agropecuária.

EMCAPER - Empresa Capixaba de Pesquisa Agropecuária e Extensão Rural.

FASE - Federação de Órgãos para a Assistência Social e Educacional.

FBDS - Fundação Brasileira para o Desenvolvimento Sustentável.

FINDES - Federação das Indústrias do Espírito Santo.

FSC - Forest Stewardship Council.

IBASE - Instituto Brasileiro de Análises Sociais e Econômicas.

IFIR - International Forest Industry Roundtable.

IIED - International Institute for Environmental and Development.

IPEF - Instituto de Pesquisas e Estudos Florestais.

IPF - Intergovernmental Panel on Forests.

IUFRO - International Union of Forestry Research Organizations.

NISI - Núcleo Interinstitucional de Saúde Indígena.

PEFC - Pan European Forest Certification System.

SBS - Sociedade Brasileira de Silvicultura.

SEAMA - Secretaria de Estado para Assuntos do Meio Ambiente do Espírito Santo.

SIF - Sociedade de Investigação Florestal.

TR14061 - Documento guia da ISO 14000 para Manejo Florestal Sustentável.

WBCSD - World Business Council for Sustainable Development.

WG2 - Grupo de Trabalho do Comitê Técnico-207 (TC-207) da ISSO, responsável pela ISO 14001.

WWF - World Wild Fund. 